CLINICAL STUDY

\title{
Reduced microvascular perfusion and reactivity in adult GH deficient patients is restored by GH replacement
}

\author{
V Hána, M Prázný, J Marek, J Škrha and V Justová \\ Third Department of Internal Medicine, Faculty of Medicine I, Charles University, Prague, Czech Republic \\ (Correspondence should be addressed to V Hána, Third Department of Internal Medicine, Faculty of Medicine I, Charles University, U nemocnice 1, \\ 12821 Prague 2, Czech Republic; Email: vhana@If1.cuni.cz)
}

\begin{abstract}
Background: An increased cardiovascular risk and mortality in hypopituitary patients receiving conventional hormonal treatment without GH replacement have been shown in several studies. Various atherogenic risk factors including endothelial dysfunction - an early event in the atherogenesis - are more expressed in adults with GH-deficiency (GHD). Changes in microcirculation and vascular reactivity could represent an early marker of developing vascular changes.

Objective: To evaluate the microcirculation and vascular reactivity in a GHD state before and during GH replacement.

Subjects, methods and design: Thirteen adult patients (ten men, mean age $40 \pm 9$ years) with severe GHD were studied. The skin microvascular perfusion and reactivity were measured by laser-Doppler flowmetry on the forearm. Two dynamic tests for vascular perfusion and reactivity were used - postocclusive reactive hyperemia (PORH) and thermal hyperemia (TH) at $44^{\circ} \mathrm{C}$. Measurements were performed before and after 6 and 12 months on GH replacement with a dose of GH that normalized IGF-I serum levels. The parameters of tissue perfusion and vascular reactivity measured in GHD were compared with values during GH treatment and with the results of the control group.

Results: Peak flow during TH in GHD patients was significantly reduced before GH treatment when compared with healthy subjects (means \pm s.E.M., $68 \pm 6.6$ vs $111 \pm 8.3$ perfusion units (PU),

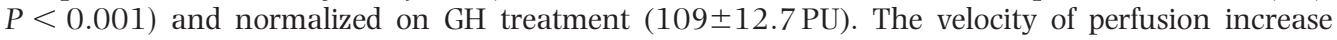
during TH before treatment was significantly reduced in GHD as well $(0.84 \pm 0.07$ vs $1.53 \pm 0.19 \mathrm{PU} / \mathrm{s}, P<0.03)$ and normalized on $\mathrm{GH}$ treatment $(1.38 \pm 0.24 \mathrm{PU} / \mathrm{s})$. The PORH was also significantly reduced in GHD compared with controls $\left(\mathrm{PORH}_{\max } 414 \pm 63\right.$ vs 528 $58 \%$, $P<0.05)$ and during GH treatment was restored to values not different from controls $(642 \pm 86 \%$, $P=\mathrm{NS}$ ).

Conclusions: Skin microcirculation and vascular reactivity measured by laser-Doppler flowmetry is significantly reduced in GHD adults and is restored during GH replacement therapy. Reduced tissue perfusion and reactivity probably reflect the endothelial dysfunction in the GHD state. Reduced nitric oxide production and bioavailability and also other factors like increased sympathetic activity and reduced conversion of thyroxine to triiodothyronine in the GHD state can contribute to changes in microcirculation. Restoration of vascular reactivity by GH replacement might have favorable clinical consequences on the increased vascular morbidity of GHD patients. Reduced skin microvascular perfusion and reactivity in GHD probably contribute to the impaired thermoregulation - a clinical symptom of GHD.
\end{abstract}

European Journal of Endocrinology 147 333-337

\section{Introduction}

An increased morbidity and mortality have been detected in hypopituitary adults in several studies, with the standardized mortality rate in the range 1.2-2.17 (1-6). Explanation for this observation is not clear. Some of these studies documented an increased vascular mortality $(1,4,5)$, although some did not $(2,3,6)$. Changes in various atherogenic risk factors have been demonstrated in growth hormone (GH) deficiency (GHD) - lipids, coagulation factors, insulin resistance, blood pressure, enhanced oxidative stress, cardiac function, inflammatory markers interleukin-6 and C-reactive protein and also the endothelial dysfunction measured by flow-mediated dilatation (FMD) (7-9). Endothelial dysfunction is considered to be an early marker of atherogenesis. Endothelium is a very active secretory organ producing 
many substances influencing various processes. One of its key functions is the regulation of blood circulation. Changes in the endothelial function can be manifest for instance by changes in the endothelium-dependent vascular reactivity.

Measuring skin microvascular reactivity by laserDoppler flowmetry (LDF) is a method for assessing dynamic parameters of tissue perfusion to the depth of approximately $1 \mathrm{~mm}$. Perfusion can be thus observed in skin capillaries, arterioles, venules and in arteriovenous shunts. LDF is performed non-invasively, is easy for both patients and staff and gives reproducible results. LDF is used, for instance, in plastic surgery to assess the viability of transplanted grafts of skin, in diabetology for evaluation of microangiopathy, in angiology for the diagnosis of Raynaud's syndrome and for evaluation of tissue perfusion in other fields of medicine. The use of LDF remains currently mostly in clinical research and the indications for daily practice are under evaluation. The most important factors influencing LDF measurements are the room and skin temperature, smoking, vasoactive medication, and any mental stress which could cause peripheral vasoconstriction.

The aim of the study was to evaluate the microcirculation and vascular reactivity in a GHD state before and during GH replacement. Changes in microcirculation and vascular reactivity could represent an early marker of developing vascular changes.

\section{Study protocol, patients and methods}

Thirteen adult patients (ten men, mean age $40 \pm 9$ years, body mass index (BMI) $28.4 \pm 3.5 \mathrm{~kg} / \mathrm{m}^{2}$ ) with severe GHD $(\mathrm{GH}<3 \mu \mathrm{g} / \mathrm{l}$ during an insulin tolerance test) were studied. Two patients had childhood-onset GHD and the rest adult-onset GHD. The causes of GHD were non-functioning pituitary adenoma and its treatment (in seven patients), prolactinoma (two), idiopathic hypopituitarism (two), pituitary adenoma with acromegaly (one) and with Cushing's disease (one) both inactive after treatment. All the patients were normotensive, non-diabetics, non-smokers and were not using drugs influencing vascular perfusion (except for adequate replacement of hypopituitarism). All the patients were on stable replacement therapy six on gonadal, hydrocortisone, thyroid and desmopressin replacement, four patients on replacement of three axes, one of two axes, two of one axis.

The skin microvascular perfusion and reactivity were measured by LDF on the forearm. Two dynamic tests for microvascular reactivity were used - postocclusive reactive hyperemia $(\mathrm{PORH})$ and thermal hyperemia (TH) at $44^{\circ} \mathrm{C}$. Measurements were performed before and after 6 and 12 months on $\mathrm{GH}$ replacement with a stable dose of $\mathrm{GH}$ that normalized insulin-like growth factor-I (IGF-I) serum levels. The dose of GH was at the beginning titrated to get IGF-I into the normal range. Mean stable GH dose was $0.92 \pm 0.45 \mathrm{IU} /$ day (mean \pm S.D., range $0.4-2.0$ ). The parameters of tissue perfusion and vascular reactivity measured in GHD were compared with values during $\mathrm{GH}$ replacement and with the results of the control group consisting of 18 healthy subjects (nine men, mean age $46 \pm 9$ years). There were no significant differences in the microcirculation parameters between sexes in the control group.

LDF measurements were performed using a Periflux 4001 apparatus (Perimed, Järfälla, Sweden) after overnight fasting on all persons between 0800 and $0900 \mathrm{~h}$ after at least $30 \mathrm{~min}$ of rest at room temperature $\left(22^{\circ} \mathrm{C}\right)$ in the sitting position. The LDF heating probe was fixed on the ventral part of the forearm. The temperature of the probe was set to $32{ }^{\circ} \mathrm{C}$ thermal stabilization of the skin and maintained by a heating unit (Peritemp 4005; Perimed). After $5 \mathrm{~min}$ of stabilization the basal flow was recorded. Occlusion of the brachial artery was then performed for $3 \mathrm{~min}$ by inflating the tourniquet of a sphygmomanometer to $20 \mathrm{mmHg}$ above the systolic blood pressure. After fast decompression the flow changes were recorded to evaluate PORH. A 5 min stabilization period was followed by increasing the skin temperature to $44^{\circ} \mathrm{C}$ by heating the probe and the course of TH was recorded.

The following parameters of microvascular reactivity were evaluated: PORH as the peak flow during hyperemia $\left(\mathrm{PORH}_{\max }\right)$ expressed in perfusion units (PU), the time necessary to reach this peak $\left(t_{1}\right)$ and the mean velocity of the perfusion increase $\left(\mathrm{PORH}_{\max } / \mathrm{t}_{1}\right)$ expressed as a ratio between perfusion increase from basal values and $t_{1}(\mathrm{PU} / \mathrm{s})$. PORH was also expressed as a ratio of peak flow and basal flow as percent of basal value. Similarly, the peak flow during TH $\left(\mathrm{TH}_{\max }\right)$ and the time necessary to reach this peak $\left(t_{2}\right)$ were used for calculation of the mean velocity of perfusion increase during $\mathrm{TH}\left(\mathrm{TH}_{\max } / \mathrm{t}_{2}\right)$ and $\mathrm{TH}$ was also expressed as percentage of basal flow. The reproducibility of LDF measurements estimated by repeated measurements in healthy volunteers during 10 consecutive days was characterized by day-to-day variation of the variables below $10 \%$.

The method used for biochemical measurement of IGF-I was IRMA after acid-ethanol extraction.

All the performed studies were in accordance with the Helsinki Declaration of 1975, as revised in 1983; the study was approved by the Faculty of Medicine I ethics committee and the studied subjects gave written informed consent.

\section{Statistics}

Descriptive data are expressed as means \pm S.D. and the results as means \pm S.E.M. The GHD patients were compared with the control group using an independent two-sample $t$-test. A paired $t$-test was used to analyze 
Table 1 Microcirculation parameters of GHD patients before and during GH replacement and of the controls.

Data are means \pm S.E.M.

\begin{tabular}{|c|c|c|c|c|}
\hline & \multicolumn{3}{|c|}{ GHD patients } & \multirow[t]{2}{*}{ Controls } \\
\hline & Before GH & 6 months' GH & 12 months' GH & \\
\hline $\mathrm{TH}_{\max }(\mathrm{PU})$ & $68 \pm 6.6^{x}$ & $104 \pm 15.4^{c}$ & $109 \pm 12.7^{c}$ & $111 \pm 8.3$ \\
\hline $\mathrm{TH}_{\max } / \mathrm{t}_{2}(\mathrm{PU} / \mathrm{s})$ & $0.84 \pm 0.07^{z}$ & $1.52 \pm 0.32$ & $1.38 \pm 0.24$ & $1.53 \pm 0.19$ \\
\hline $\mathrm{TH}(\%)$ & $1060 \pm 228^{y}$ & $1805 \pm 207^{b, y}$ & $1792 \pm 225^{z}$ & $1341 \pm 106$ \\
\hline $\mathrm{PORH}_{\max }(\mathrm{PU})$ & $34 \pm 4.9^{z}$ & $37 \pm 7.0$ & $39 \pm 6.3$ & $49 \pm 4.5$ \\
\hline $\mathrm{PORH}_{\max } / \mathrm{t}_{1}(\mathrm{PU} / \mathrm{s})$ & $3.36 \pm 0.78$ & $3.19 \pm 0.74$ & $4.94 \pm 1.28$ & $4.38 \pm 0.47$ \\
\hline PORH (\%) & $414 \pm 63^{z}$ & $514 \pm 53^{b}$ & $642 \pm 86$ & $528 \pm 58$ \\
\hline
\end{tabular}

Statistical significance of differences between patients and controls: ${ }^{\mathrm{x}} P<0.001,{ }^{\mathrm{y}} P<0.01,{ }^{\mathrm{z}} P<0.05$ and between patients before and during treatment: ${ }^{\mathrm{a}} P<0.001,{ }^{\mathrm{b}} P<0.01,{ }^{\mathrm{c}} P<0.05$.

changes within individuals as a result of GH therapy. Statistical significance was inferred at $P<0.05$.

\section{Results}

Thirteen patients were studied before and after 6 months and 12 patients after 12 months of $\mathrm{GH}$ replacement therapy; one patient withdrew from the study after 6 months. Reduced pretreatment IGF-I levels normalized during GH treatment from $135 \pm 79 \mu \mathrm{g} / \mathrm{l}$ (mean \pm S.E.M.) to $269 \pm 67 \mu \mathrm{g} / \mathrm{l}$ $(P<0.01)$ after 6 months and $272 \pm 78 \mu \mathrm{g} / \mathrm{l}$ after 12 months $(P<0.01)$. There were no significant changes in BMI or blood pressure values during treatment.

Parameters of forearm microcirculation measured by LDF in GHD patients before GH therapy were significantly reduced in comparison with control subjects and restored on GH treatment (Table 1, Figs 1 and 2).

\section{Discussion}

This is the first study demonstrating the reduced skin perfusion and impaired microvascular reactivity

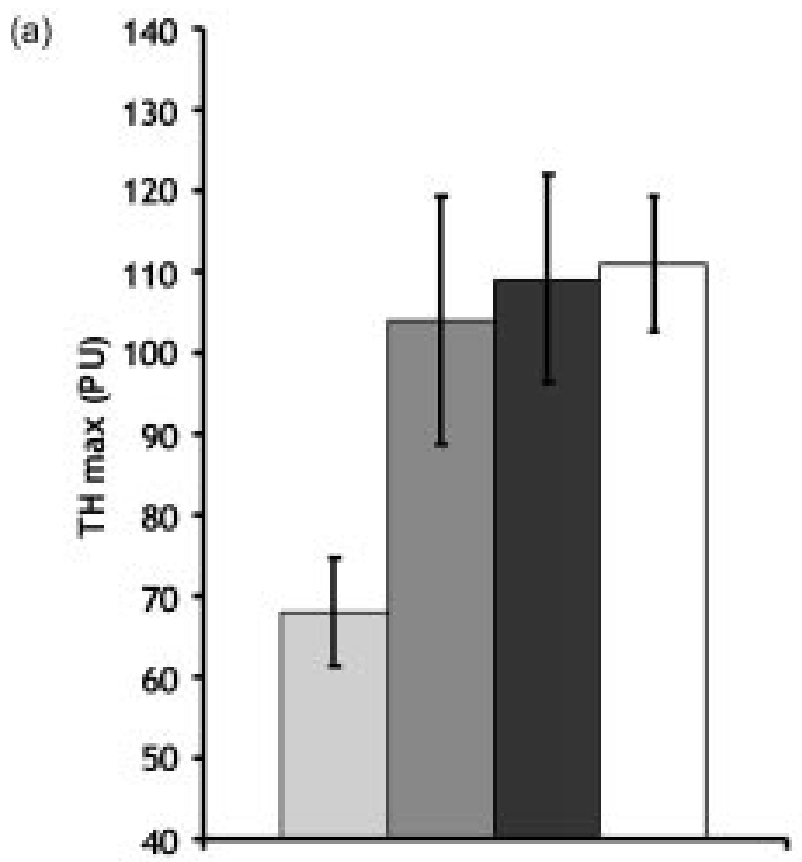

$\square \mathrm{GH} 0 \mathrm{GGH} 6 \mathrm{GGH} 12 \square \mathrm{C}$ (b)

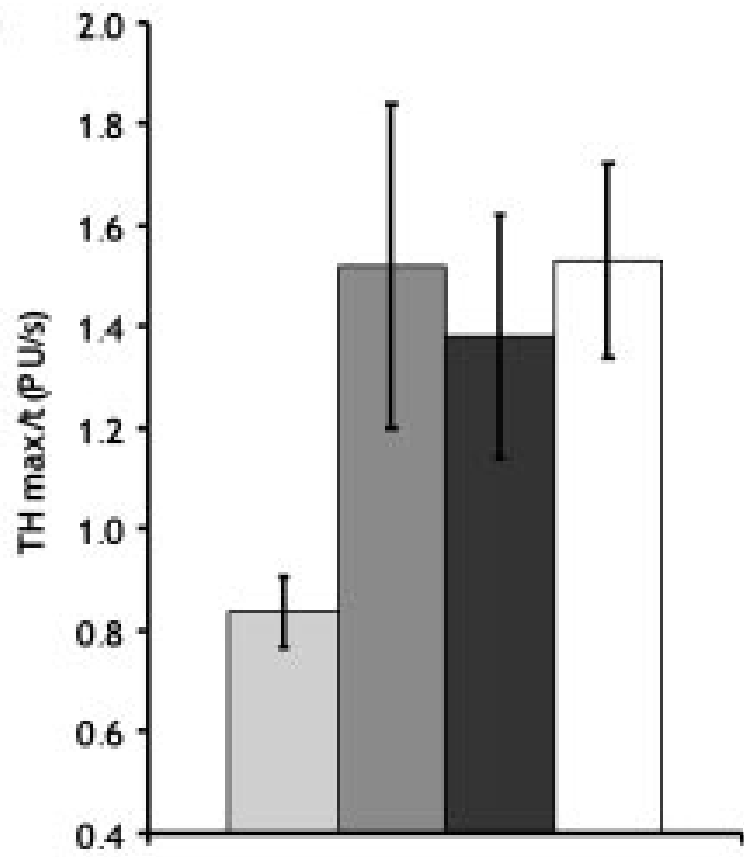

$\square \mathrm{GH} 0 \square \mathrm{GH} 6 \mathrm{GGH} 12 \square \mathrm{C}$

Figure 1 (a) The comparison of maximal flow during $\mathrm{TH}\left(\mathrm{TH}_{\max }\right)$ between controls $(\mathrm{C})$ and $\mathrm{GHD}$ patients before $(\mathrm{GH})$ and during $\mathrm{GH}$ therapy (GH6 and GH12) (means \pm S.E.M.). $P<0.001$ between patients before GH and controls. (b) The comparison of the velocity of flow increase during $\mathrm{TH}\left(\mathrm{TH}_{\max } / \mathrm{t}_{2}\right)$ between controls $(\mathrm{C})$ and $\mathrm{GHD}$ patients before $(\mathrm{GH} 0)$ and during $\mathrm{GH}$ therapy $(\mathrm{GH} 6$ and $\mathrm{GH} 12)$. $P<0.05$ between patients before $\mathrm{GH}$ and controls. 


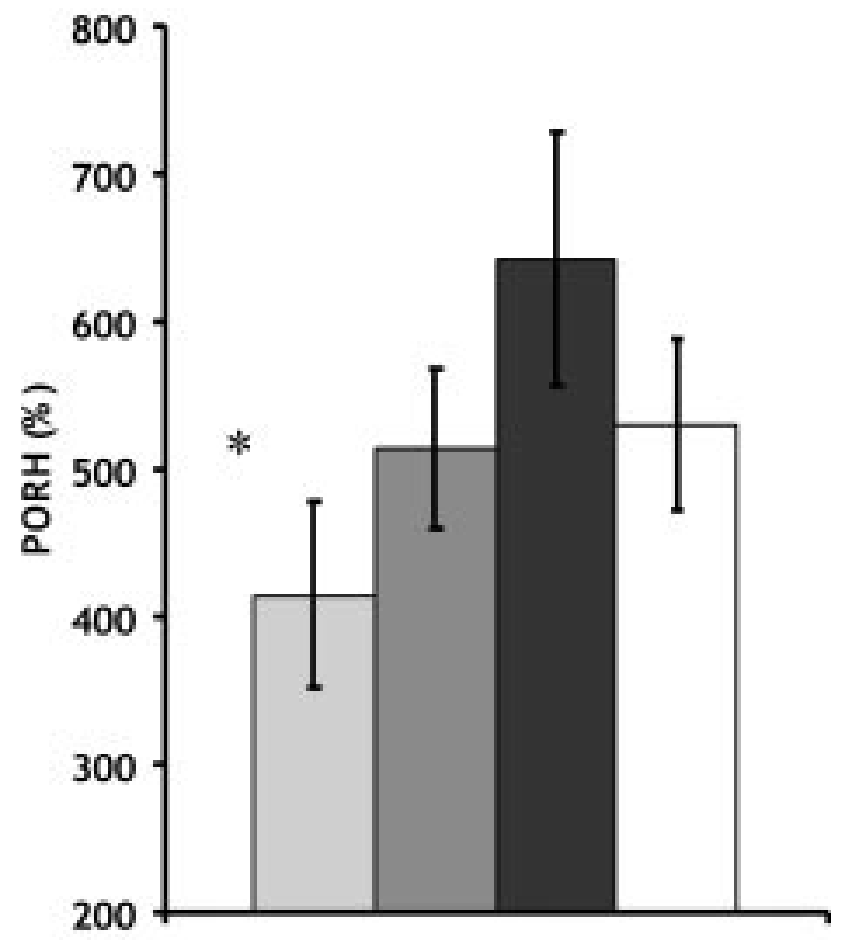

口GH 0 QGH $6 \square \mathrm{GH} 12 \square \mathrm{C}$

Figure 2 The comparison of PORH between controls (C) and GHD patients before $(\mathrm{GHO})$ and during $\mathrm{GH}$ replacement therapy (GH6 and $\mathrm{GH} 12)$. ${ }^{*} P<0.05$ between patients before $\mathrm{GH}$ and control.

measured by LDF in GHD patients and its restoration on GH replacement. We are not aware of any other study using this technique in adult GHD patients to compare with. Several studies have proved an impaired endothelium-dependent FMD of the brachial artery in GHD patients while endothelium-independent vasodilatation was similar to that of controls $(7,8,10)$. Results of FMD induced by shear stress are known to be dependent on endothelium-derived production of nitric oxide (NO) (11). A systemic NO production is reduced in the GHD state and it normalizes on GH replacement (12). Vasodilatation stimulated by IGF-I can be completely reversed by NO synthase inhibitor $\mathrm{N}^{\mathrm{G}}$-monomethyl-Larginine, indicating that the mediators of $\mathrm{GH}$ action on blood flow are IGF-I, NO synthase and NO (13). Similar to the effect of GH replacement on FMD measured on the brachial artery, we suggest a key role for the IGF-I-NO synthase-NO axis in the regulation of microcirculation as well. Mainly the shear stress during PORH test is considered to demonstrate the endothelium-dependent FMD. Not only production of NO but also NO bioavailability can modify the vasomotion. The elevated levels of free radicals in GHD can reduce NO bioavailability and vasoreactivity (8). Reduction of increased oxidative stress and restoration of $\mathrm{NO}$ bioavailability during $\mathrm{GH}$ treatment
(8) is another plausible mechanism improving microcirculation.

However, other factors could also contribute to the changes in microvascular reactivity and blood flow in the GHD state. An increased sympathetic activity described in GHD (14) can enhance vasoconstriction and reduce microvascular perfusion in the GHD state. Reduction of an increased sympathetic activity during GH therapy can positively influence tissue perfusion (14). The other factor influencing the microcirculation is the thyroid hormone status. Skin perfusion measured on LDF is increased in hyperthyroid patients and decreased in hypothyroid patients (15). GH replacement stimulates peripheral conversion of thyroxine $\left(\mathrm{T}_{4}\right)$ to the active hormone triiodothyronine $\left(\mathrm{T}_{3}\right)$ in GHD adult patients (16). This shift to higher levels of $\mathrm{T}_{3}$ in tissues might also contribute to the increase in the microcirculation.

Adult GHD is associated with an abnormal body composition by reduced lean body mass, reduced total body water (TBW) and increased fat mass. GH replacement therapy increases TBW, plasma volume (PV) and total blood volume (TBV) (17) and this evokes speculations about possible relationships with changes in microcirculation. Mean changes in these parameters in the 3 month study of Christ et al. (17) were: TBW $2.5 \pm 0.53 \mathrm{~kg}$ (mean \pm S.E.M.), PV $350 \pm 117 \mathrm{ml}$ and TBV $515 \pm 109 \mathrm{ml}$. Whether these changes in hydration contribute to the changes in microcirculation has not been studied yet. An acute $450 \mathrm{ml}$ blood loss is not associated with the change in cutaneous microcirculation measured by LDF (18); however, the effect of long-term change in TBV and PV is not known.

The main increase in the parameters of tissue microcirculation in our study was seen in the data from the dynamic tests representing the vascular reactivity, while the basal microcirculation data were not significantly changed by GH therapy. The relationship of these parameters in TH and PORH tests is reflected by the relative expression of data as a ratio of peak flow and basal flow as a percent of basal values. Restoration of vascular reactivity by $\mathrm{GH}$ replacement we suppose to represent the improvement of the endothelial dysfunction, an early marker of atherosclerosis. This might have a favorable clinical effect on the increased vascular morbidity of GHD patients.

There is an interesting observation of Maison et al. (19), who found an impaired endothelium-dependent vasodilatation using the method of LDF in active acromegalic patients. Acromegalics are known to have an increased cardiovascular morbidity and mortality (20). It seems that both deficiency and excess of GH negatively influence endothelial function and hence contribute to cardiovascular risk factors in these states.

The observed reduced skin microvascular perfusion and reactivity in GHD patients might also contribute to the pathophysiology of the clinical symptoms of 
GHD syndrome-impaired thermoregulation, reduced sweating and increased body heat storage (21).

We conclude that the tissue microvascular perfusion and reactivity are reduced in adult GHD syndrome and are restored on $\mathrm{GH}$ replacement. The stimulatory effect of $\mathrm{GH}$ replacement on the microcirculation is probably mediated by all the above mentioned mechanisms improved endothelial function with increased NO production and bioavailability, changes in sympathetic tone and increased $\mathrm{T}_{4}$ to $\mathrm{T}_{3}$ conversion.

\section{Acknowledgements}

The authors are indebted to Dr T Haas for his statistical analysis support. The study was supported by the Research Project of the Ministry of Education, Czech Republic, No. J13/98 111100002 (206017).

\section{References}

1 Rosen T \& Bengtsson BA. Premature mortality due to cardiovascular disease in hypopituitarism. Lancet 1990336 285-288.

2 Bates AS, Van't Hoff W, Jones PJ \& Clayton RN. The effect of hypopituitarism on life expectancy. Journal of Clinical Endocrinology and Metabolism 199681 1169-1172.

3 Bates AS, Bullivant B, Sheppard MC \& Stewart PM. Life expectancy following surgery for pituitary tumours. Clinical Endocrinology 199950 315-319.

4 Bulow B, Hagmar L, Mikoczy Z, Nordstrom CH \& Erfurth EM. Increased cerebrovascular mortality in patients with hypopituitarism. Clinical Endocrinology $1997 \mathbf{4 6} 75-81$.

5 Nilsson B, Gustavsson-Kadaka E, Bengtsson BA \& Jonsson B. Pituitary adenomas in Sweden between 1958 and 1991: incidence, survival, and mortality. Journal of Clinical Endocrinology and Metabolism 200085 1420-1425.

6 Tomlinson JW, Holden N, Hills RK, Wheatley K, Clayton RN, Bates A et al. Association between premature mortality and hypopituitarism. Lancet 2001357 425-431.

7 Evans LM, Davies JS, Godfellow J, Rees JAE \& Scanlon MF. Endothelial dysfunction in hypopituitary adults with growth hormone deficiency. Clinical Endocrinology 199950 457-464.

8 Evans LM, Davies JS, Anderson RA, Ellis GR, Jackson SK, Lewis MJ et al. The effect of GH replacement therapy on endothelial function and oxidative stress in adult growth hormone deficiency. European Journal of Endocrinology 2000142 254-262.

9 Sesmilo G, Biller BMK, Llevadot J, Hayden D, Hanson G, Rifai N et al. Effects of growth hormone administration on inflammatory and other cardiovascular risk markers in men with growth hormone deficiency. Annals of Internal Medicine $2000 \mathbf{1 3 3}$ 111-122.

10 Pfeifer M, Verhovec R, Žižek B, Preželj J, Poredoš P \& Clayton RN. Growth hormone treatment reverses early atherosclerotic changes in GH-deficient adults. Journal of Clinical Endocrinology and Metabolism $1999 \mathbf{8 4} 453-457$.

11 Celermajer D, Sorenson K, Gooch V, Spegelhalter D \& Deanfield J. Non-invasive detection of endothelial dysfunction in children and adults at risk of atherosclerosis. Lancet $1992 \mathbf{3 4 0}$ 1111-1115.

12 Böger RH, Skamira C, Bode-Böger SM, Brabant G \& von zur Mühlen. Nitric oxide may mediate the hemodynamic effects of recombinant growth hormone in patients with acquired growth hormone deficiency. Journal of Clinical Investigation 199698 2706-2713.

13 Fryburg DA. NG-Monomethyl-L-arginine inhibits the blood flow but not the insulin-like response of forearm muscle to IGF-1. Possible role of nitric oxide in muscle protein synthesis. Journal of Clinical Investigation 199697 1319-1328.

14 Sverrisdóttir YB, Ekam M, Bengtsson B-A \& Johansson G. Intense sympathetic nerve activity in adults with hypopituitarism and untreated growth hormone deficiency. Journal of Clinical Endocrinology and Metabolism $1998 \mathbf{8 3} 1881-1885$.

15 Weiss M, Milman B, Rosen B \& Zimlichman R. Quantitation of thyroid hormone effect on skin perfusion by laser Doppler flowmetry. Journal of Clinical Endocrinology and Metabolism 1993 76 680-682.

16 Jorgensen JO, Pedersen SA, Laurberg P, Weeke J, Skakkebaek NE \& Christiansen JS. Effects of growth hormone therapy on thyroid function of growth hormone-deficient adults with and without concomitant thyroxine-substituted central hypothyroidism. Journal of Clinical Endocrinology and Metabolism $1989 \quad 69$ $1127-1132$

17 Christ ER, Cummings MH, Westwood NB, Sawyer BM, Pearson TC, Sönksen PH et al. The importance of growth hormone in the regulation of erythropoiesis, red cell mass, and plasma volume in adults with growth hormone deficiency. Journal of Clinical Endocrinology and Metabolism $1997 \mathbf{8 2}$ 2985-2990.

18 Janetzko K, Kluter H, Kirchner H \& Klotz KF. The effect of moderate hypovolaemia on microcirculation in healthy older blood donors. Anaesthesia 200156 103-107.

19 Maison P, Démolis P, Young J, Schaison G, Giudicelli J-F \& Chanson P. Vascular reactivity in acromegalic patients: preliminary evidence for regional endothelial dysfunction and increased sympathetic vasoconstriction. Clinical Endocrinology 200053 445-451.

20 Orme SM, McNally RJQ, Cartwright RA \& Belchetz PA. Mortality and cancer incidence in acromegaly: a retrospective cohort study. Journal of Clinical Endocrinology and Metabolism $1998 \mathbf{8 3}$ $2730-2734$

21 Juul A, Hjortskof N, Jepsen LT, Nielsen B, Halkjaer-Kristensen J, Vahl $\mathrm{N}$ et al. Growth hormone deficiency and hyperthermia during exercise: a controlled study of $16 \mathrm{GH}$-deficient patients. Journal of Clinical Endocrinology and Metabolism $1995 \mathbf{8 0}$ 3335-3340.

Received 9 November 2001

Accepted 12 June 2002 